\title{
Getting Expressivism Out of THE WoOds
}

\author{
SARAH ZOE RASKOFF
}

In a recent paper, Jack Woods (2014) advances an intriguing argument against expressivism based on Moore's paradox. Woods argues that a central tenet of expressivism - which he, following Mark Schroeder (2008a), calls the parity thesisis false. The parity thesis is the thesis that moral assertions express noncognitive, desire-like attitudes like disapproval in exactly the same way that ordinary, descriptive assertions express cognitive, belief-like attitudes. Most contemporary defenders of expressivism seem not only to accept the parity thesis but also to rely on it to distinguish their view from subjectivism, so Woods's argument against it poses a serious challenge to the view. In this paper, I argue that Woods's argument is unsuccessful, but show that diagnosing precisely where it goes wrong raises interesting questions for expressivists - and metaethicists more generally - about the transparency of our moral attitudes.

\section{Introduction}

In a recent paper, Jack Woods (2014) advances an intriguing argument against expressivism based on Moore's paradox. Woods argues that a central tenet of expressivism - which he, following Mark Schroeder (2008a), calls the parity thesis - is false. The parity thesis is the thesis that moral assertions express noncognitive, desire-like attitudes like disapproval in exactly the same way that ordinary, descriptive assertions express cognitive, belief-like attitudes. ${ }^{1}$ Most con-

1. Woods actually characterizes the parity thesis as "the thesis that moral assertions express noncognitive attitudes like disapproval in exactly the same way that non-moral assertions express cognitive attitudes like belief" (2014: 3). In this paper I follow Mark Schroeder and use 'descriptive' rather than 'non-moral' for the simple reason that doing so makes both the parity thesis, as well as Woods's argument against it, easier to understand and articulate. Nothing about my objection to Woods depends on this switch. It is nevertheless important to be clear that Woods explicitly states that his target in the paper is expressivism about the moral and not expressivism about, for instance, epistemic modality ('It might be raining outside') or about the normative in general ('All

Contact: Sarah Raskoff <sraskoff@email.arizona.edu> 
temporary defenders of expressivism seem not only to accept the parity thesis but also to rely on it to distinguish their view from subjectivism, so Woods's argument against it poses a serious challenge to the view. In this paper, I argue that Woods's argument is unsuccessful, but show that diagnosing precisely where it goes wrong raises interesting questions for expressivists - and metaethicists more generally-about the transparency of our moral attitudes. ${ }^{2}$

Here is how the paper goes. In Section 2, I introduce expressivism and the parity thesis. In Section 3, I outline Woods's case against the parity thesis. In Section 4, I raise a quick response to Woods's argument: I suggest that the argument is unsuccessful because it presupposes that expressivism is transparent to ordinary speakers - that is, it presupposes that ordinary speakers recognize that our moral beliefs are identical with noncognitive, desire-like attitudes. ${ }^{3}$ In Sections 5 and 6, I consider Woods's preferred solution to Moore's paradox, and argue that it is incomplete since it accounts only for the absurdity of asserting a Moorean proposition, and not for the absurdity of believing one. I defend a popular alternative solution to the paradox that avoids this problem by explaining the absurdity of asserting a standard Moorean proposition like 'it is raining but I don't believe it' in terms of the absurdity of believing one. In the remainder of the paper (Sections 7, 8, and 9), I draw on this solution to the paradox to provide a theoretical explanation of why the absence of transparency offers expressivists a way to block Woods's argument against the parity thesis based on Moore's paradox. I conclude with some brief, exploratory remarks about the transparency of our moral attitudes.

\section{Expressivism, Expression, and the Parity Thesis}

Before we get to Woods's argument, a few introductory remarks about expressivism are in order. Like Woods, I will talk as if defenders of expressivism accept a single view, though of course 'defenders of expressivism' picks out a motley

things considered, I really ought to stay in tonight to grade these logic exams'). For representative examples of defenders of metaethical expressivism committed to the parity thesis, see Allan Gibbard (2003: 64) and Simon Blackburn (1984: 169).

2. See Teemu Topinnen $(2014 ; 2015)$ for a different response to Woods's argument, and Woods (2015) for his reply.

3. Most contemporary expressivists continue to call moral judgments "beliefs" despite denying that they are the same attitudes as ordinary, descriptive beliefs (which are not, of course, noncognitive attitudes). This is part of the quasi-realist project of attempting to "earn the right" to use all the same language as the cognitive moral realists. (See Blackburn 1984.) I will adopt this same practice myself in what follows, but for an intriguing discussion of quasi-realism, see Dreier (2004). 
crew of philosophers whose views differ in subtle ways. 4 For the purposes of this paper, let 'expressivism' be the metaethical view according to which (i) moral utterances such as 'murder is wrong' do not express beliefs that could be true or false in a robust, non-deflationary sense; and (ii) instead, moral utterances express noncognitive, desire-like attitudes such as approval or disapproval. For simplicity, let us assume that the relevant noncognitive attitude is disapproval, so that 'murder is wrong' expresses the speaker's disapproval of murder. Then, according to the expressivist, to judge that murder is wrong not to have a belief about murder, but rather to disapprove of murder. And to express this judgment is not express a belief but rather to express disapproval.

Central to the expressivist view is the idea that we can express our attitudes without reporting that we have them. When I assert 'murder is wrong,' I am not reporting that I disapprove of murder, but rather expressing my disapproval. This is what distinguishes expressivism from cognitivist speaker subjectivism, according to which a sincere assertion of 'lying is wrong' reports an attitude, and therefore has the same meaning - or at least, the same truth conditions - as a sincere assertion of 'I disapprove of lying'. 5 But what exactly is it for an assertion to express a noncognitive, desire-like attitude rather than report it? The critical expressivist move is to appeal to the parity thesis. The answer the parity thesis offers is that we are already familiar with the idea that assertions express without reporting attitudes; namely, assertions of ordinary, descriptive statements express cognitive attitudes such as belief. If I believe that it is raining, uttering 'it is raining' is different than stating 'I believe that it is raining', though both bear some relation to the same belief. The former expresses my belief that it is raining, while the latter reports it. To accept the parity thesis is just to maintain that sincere assertions of moral statements express noncognitive, desire-like attitudes in exactly the same way as ordinary, descriptive statements express cognitive attitudes like beliefs, however that might be. Whatever relation holds between a sincere assertion of 'it's raining' and the speaker's belief that it's raining, the same one holds between a sincere assertion of 'murder is wrong' and the speaker's disapproval of murder. And the same relation also holds between a sincere utterance of 'hooray!' and a speaker's noncognitive, positive attitudes. As we will see, the parity between these three different types of expression-expressing beliefs, expressing moral disapproval in expressivist fashion, and expressing more mundane noncognitive attitudes such as whatever 'hooray!' expresses-plays an essential role in Woods's argument.

4. See, for example, Gibbard (1990) and Blackburn (1984; 1992; 1998).

5. For a careful discussion of the differences between expressivism and subjectivism, see Mark Schroeder's (2008a; 2008b; 2014). 


\section{Woods versus the Parity Thesis}

The standard case of Moore's paradox arises for propositions of the form $<p$, but I don't believe that $p>.6$ Call propositions of this form Moorean propositions. Moore observed that assertions of Moorean propositions seem "absurd" or selfdefeating in much the same way as assertions of contradictions, even though Moorean propositions are not contradictory. ${ }^{7}$ For instance, it's easy to imagine a scenario in which it's raining but I fail to believe that it's raining. For Moore, it is a "paradox" that it is absurd to assert such a possible truth. ${ }^{8}$ And the puzzle of Moore's paradox is to explain this absurdity.

Woods thinks that the presence or absence of the absurdity characteristic of standard cases of Moore's paradox is an adequate test of the truth of the parity thesis. Here is my reconstruction of Woods's argument against the parity thesis:

1. If the parity thesis is true, a sincere assertion of 'murder is wrong, but I don't disapprove of murder' will produce the same absurdity as a sincere assertion of ' $p$, but I don't believe that $p$ '.

2. It is not absurd to assert sincerely 'murder is wrong, but I don't disapprove of murder'.

3. So, the parity thesis is false.

Woods seems to think that premise 2 is the crux of the argument, since he spends the majority of his paper making the case that it is not absurd to assert 'murder is wrong, but I don't disapprove of it'. Much more important for his argument, however, is premise 1 , according to which Moore's paradox is a good test of the parity thesis. And unfortunately, Woods does not have much to say in its favor. His defense for this claim focuses on a set of statements that, according to Woods, generate the absurdity characteristic of standard cases of Moore's paradox. Woods considers:

6. Woods's argument focuses on the omissive form of Moore's paradox, so called because an assertion of ' $p$, but I don't believe that $p$ ' reports the specific omission of true belief. In this paper, I follow Woods's lead, but it is worth pointing out that Moore also observed that to say, 'I believe that he has gone out, but he has not' would also be 'absurd' (1946: 204). This is the commissive form, so called because an assertion of ' $p$, but I believe that not- $p$ ' reports the commission of a specific mistake in belief.

7. More carefully, Moorean propositions are paradoxical because even though they can be true, assertions of them are absurd in a way that cannot be fully explained in terms of a semantic contradiction generated by the words of the proposition.

8. Moore put it like this: "It is a paradox that it should be perfectly absurd to utter assertively words of which the meaning is something which may quite well be true-is not a contradiction" (2013: 209).

Ergo vol. 5, no. $36 \cdot 2018$ 
(A) Go Red Sox! I don't support the Red Sox.

(B) Fuck the Yankees! I don't have any negative attitude towards the Yankees.

(C) Murder is wrong, but I don't believe that murder is wrong.

(D) It's raining, but I don't believe that it's raining. 9

Woods claims that (A-D) all generate the absurdity characteristic of standard cases of Moore's paradox. Now (C) and (D) are standard Moorean propositions, so it is no surprise that they generate the absurdity characteristic of standard cases of Moore's paradox. (A) and (B), however, contain interjections in the place of statements in the indicative. In this way, (A) and (B) are not standard Moorean propositions. Even so, Woods contends that sincere utterances of (A) or (B) reproduce the very same absurdity as sincere assertions of $(C)$ or $(D) .{ }^{10}$ Woods explains,

These examples indicate that we can reproduce cases of the incoherence present in the standard Moore-paradoxical constructions without using sentences in the indicative. Ejaculations like 'Go Red Sox!' are not usually considered assertions, but they give rise to the same incoherence when paired with a denial of possessing the relevant backing attitude of approval. Sincere utterance of 'Go Red Sox' thus plausibly requires the possession of some degree of enthusiasm and approval for the team. (2014: 5)

The suggestion in this passage is that because sincerely uttering 'Go Red Sox!' expresses the speaker's support of the Red Sox, pairing this utterance with a sincere assertion of 'I don't support the Red Sox' reproduces the very same absurdity we find in standard cases of Moore's paradox. In other words, (A) and (B) are defective because when a sincere utterance expresses that the speaker is in a mental state $p$, conjoining this utterance with the denial of being in $p$ yields the absurdity characteristic of standard cases of Moore's paradox like (C) and (D). (A) and (B) play an important role in Woods's argument, and in what follows, I shall refer to them as emotive Moorean propositions for the simple reason that the attitudes they express are more similar to those expressed by interjections like 'Boo!' and 'Hooray!'.

The fact that $(A)$ and $(B)$ reproduce the same absurdity as $(C)$ and $(D)$ is sup-

9. (A-C) are lifted directly from Woods's paper (2014: 5). (D) is a standard case of Moore's paradox.

10. I use 'utter' rather than 'assert' here because interjections such as 'Go Red Sox!' express noncognitive attitudes that lack propositional content. Utterances express attitudes that may but need not have propositional content. Assertions, on the other hand, are utterances that necessarily express propositional content. Henceforth, I'll use 'utterances' for any set of propositions that includes (A) and (B) to respect this distinction. 
posed to show that the presence of Moorean absurdity is a product of the expression relation that holds between a speaker's sincere utterances and the attitudes those utterances express. It is also supposed to show that nothing about the generation of Moorean absurdity depends on whether the attitude expressed by the utterance is cognitive (the attitude of believing that it's raining) or noncognitive (the attitude of supporting the Red Sox).

The next move of Woods's argument is to claim that the characteristic Moorean absurdity present in (A-D) is absent in:

(E) Murder is wrong, but I don't disapprove of murdering.

(F) Murder is wrong, but I'm not against murdering.

(G) Murder is wrong, but I'm in favor of murdering. ${ }^{11}$

Woods remarks that although we might not hire the person who uttered (E-G) to babysit our children, "we do not find utterances of these propositions defective" in the way that we find utterances of (A-D) defective (Woods 2014: 5). Although Woods does not say much to characterize the "defect" that (A-D) possess but (E-G) lack, what he seems to have in mind is a bit of linguistic data about the way we "hear" utterances of Moorean propositions in standard cases. The linguistic data is that in standard cases, the absurdity of a Moorean assertion is immediately discernible by or obvious to the speaker who utters it, her audience, and those of us reading the article. Woods thinks that the parity thesis not only predicts the absurdity of assertions of (E-G), but also that the absurdity of these assertions should be just as "audible" and immediately discernible as it is in (A-D).

The absence of this absurdity in (E-G) is supposed to be a problem for expressivism insofar as the view is committed to the thesis that moral assertions express noncognitive attitudes in exactly the same way as ordinary, descriptive assertions express beliefs. The absurdity we find in standard cases of Moore's paradox is a symptom of the fact that ordinary, descriptive assertions express beliefs. So if the parity thesis is true, assertions of so-called expressivist Moorean propositions such as (E-G) should generate the same absurdity as assertions of standard Moorean propositions. After all, (E-G) each conjoin an assertion that expresses the speaker's being in a mental state $p$ with one that denies that the speaker is in that state. Moreover, recall that Woods takes himself to have established that (A) and (B) produce the very same absurdity as (C) and (D). This effectively blocks one natural explanation of why assertions of (E-G) are not absurd, namely, that they are not absurd because the attitude expressed by asserting 'murder is wrong' is noncognitive. For, as noted above, the attitude ex-

11. Again, these are lifted directly from Woods's paper (2014: 5). 
pressed by 'Fuck the Yankees!' is also noncognitive, and yet, Woods claims, it is just as absurd to utter (B) as it is to utter (D). Woods concludes from the fact that it is not absurd to assert expressivist Moorean propositions that it is not the case that moral assertions express noncognitive attitudes in exactly the same way as ordinary, descriptive assertions express beliefs. Thus, the parity thesis fails.

\section{A Shortcut to the Big Problem}

There is a deep problem with Woods's argument, which is that the first premise of the argument is false. Moore's paradox is not a good test of the parity thesis because we should expect assertions of expressivist Moorean propositions to generate the same absurdity as standard Moorean propositions only if the truth of expressivism were transparent to ordinary speakers. If expressivism were transparent in the requisite way, then competent users of moral language would recognize that sincere moral assertions express noncognitive attitudes. They would recognize, for instance, that whenever they believe that murder is wrong, they disapprove of murdering. Or, at the very least, they would recognize that by making sincere moral assertions they incur commitments to having certain noncognitive attitudes. But expressivism is not transparent in this way. Not even self-avowed expressivists think so.

This failure of transparency matters because-as Woods himself acknowledges -'murder is wrong, but I don't believe that murder is wrong' does generate the standard Moorean absurdity. If the correct analysis of moral judgment is broadly expressivist, then the state someone is in when she believes that murder is wrong just is the attitude of disapproving of murdering. If expressivism is true, the difference between 'murder is wrong, but I don't believe that murder is wrong' and 'murder is wrong, but I don't disapprove of murdering' is like the difference between 'Superman is dreamy, but I don't believe that Superman is dreamy' and 'Superman is dreamy, but I don't believe that Clark Kent is dreamy'. Ignorant of an important fact about Superman's true identity, Lois Lane does not realize that whatever she believes of Superman is also true of Clark Kent. This ignorance explains why 'Superman is dreamy, but I don't believe that Superman is dreamy' would strike Lois Lane as absurd while 'Superman is dreamy, but I don't believe that Clark Kent is dreamy' would not. Prior to learning that Superman is Clark Kent, Lois Lane does not recognize that if Superman is dreamy, then so too is Clark Kent. This fact would not be transparent to her, and we do not expect it to be. ${ }^{12}$

12. In fact, it is exactly this failure of transparency that makes possible the whimsical love story that develops between the two.

Ergo •vol. 5, no. 36 2018 
Expressivists may appeal to a similar failure of transparency to account for the difference between 'murder is wrong, but I don't believe that murder is wrong' and 'murder is wrong, but I don't disapprove of it'. They might claim that, with respect to this difference, ordinary speakers are like Lois Lane before she realizes exactly who's who. Like Lois Lane, ordinary speakers are ignorant of an important fact about what it is to believe that murder is wrong - namely, that what it is to believe that murder is wrong just is to disapprove of murder. ${ }^{13}$ And as it did in the case of Lois Lane, this ignorance explains why 'murder is wrong, but I don't believe that murder is wrong' strikes ordinary speakers as absurd while 'murder is wrong, but I don't disapprove of murdering' does not. Things might be different if we lived in a world in which all competent users of moral language accepted the truth of expressivism, or in the very least recognized that sincere moral assertions expressed non-cognitive attitudes. But we do not live in this world. So, it is no surprise that ordinary speakers do not recognize that a sincere assertion of 'murder is wrong' expresses the very same attitude that a sincere assertion of 'I disapprove of murdering' reports. Thus, like other problematic arguments against expressivism, Woods's argument rests on the mistaken assumption that if expressivism is true, competent users of moral language must realize that moral judgment necessarily involves some relevant noncognitive attitudes. ${ }^{14}$

In the remainder of this paper, I elaborate on this line of reasoning in order to explain how and why the failure of transparency surfaces in Woods's argument from Moore's paradox. This explanation is worthwhile, for although others have engaged with Woods's argument, none has focused carefully on the issue of transparency. ${ }^{15}$ Since Woods's case against the parity thesis focuses on

13. Cases of a posteriori identity are not the only thing that can lead to a failure of transparency. Such failures can also arise in cases of a priori identities, so long as these identities are nonobvious. For example, someone might believe that something is a right triangle without believing that it is a shape whose sides are related according to the Pythagorean theorem. This is something that has been stressed by analytic naturalists such as Frank Jackson (1998) and Steven Finlay (2014), who claim that the truth of a moral statement is determined by the (highly nonobvious) meanings of its relevant terms. So nothing turns on whether expressivists believe that the identity of moral judgments and non-cognitive attitudes is a posteriori or a priori, and I focus on a posteriori identity in the main text only because it is the more intuitive case of the two. Thanks to an anonymous referee for encouraging me to clarify this point.

14. To name a few, see Frank Jackson and Phillip Pettit (1998), Terence Cuneo (2006), Jussi Suikkanen (2009), and Jonas Olson (2010). For responses to some of these arguments, see Schroeder (2014) and James Dreier (2004). To be fair, Woods has more to say about the topic of transparency than these other authors, claiming that "ordinary people are . . . aware that moral assertions are commonly used to condemn and give vent to attitudes" (Woods 2014: 10). This is plausible, but the sort of transparency I'm concerned with requires more. It requires that ordinary people are aware that sincere moral assertions necessarily express (or "give vent to") non-cognitive attitudes such as condemnation. Thanks to an anonymous referee for urging me to discuss this distinction.

15. See the citations in Footnote 2.

Ergo vol. 5, no. $36 \cdot 2018$ 
the absurdity of standard Moorean propositions à la (D), it is worth thinking carefully about his explanation in standard cases of Moore's paradox. In the next section, I review Woods's explanation of these cases argue that this explanation is ultimately incomplete since it fails to account for all the phenomena that need accounting for. After that, I will return to emotive Moorean propositions like (A) and (B) to see whether the explanation I offer of the standard case provides insight there, too.

\section{Woods's Explanation of Moore's Paradox}

Given that his entire argument against the parity thesis is based on Moore's paradox, it is surprising how little Woods says about what generates the absurdity in standard cases like (C) and (D). It might well be true that the expression relation that holds between a sincere assertion of ' $p$ ' and the speaker's belief that $p$ is what accounts for the absurdity in standard cases of Moore's paradox, but Woods hasn't given us much to see why this is so. From what little he does say, Woods seems to think that what explains the absurdity in standard cases of Moore's paradox has to do primarily with the effects of asserting a Moorean proposition. Woods states,

The proper explanation of [Moore's paradox] is that when I assert $p$, I somehow commit myself to believing $p$, but not by asserting that I believe $p$. Because I have committed myself to believing that $p$, when I go

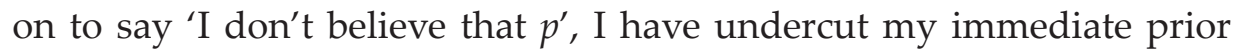
commitment and left my audience in a muddle as to what I was up to in so asserting. (2014: 2)

Woods is probably right that audiences have trouble making sense of assertions of ' $p$, but I don't believe that $p$ ', but this explanation makes it seem as if the deep problem with Moorean propositions is that assertions of them leave the audience confused about what the speaker is trying to do by asserting what she asserts and so unsure of whether to attribute to her a commitment to $p$ or a commitment to not- $p .{ }^{16}$ This explanation of Moore's paradox is fine as far as it goes,

16. I qualified with 'probably' here for the simple reason that I am not actually sure just how immediately obvious the absurdity of Moore's paradox is to ordinary speakers and audiences. I took it upon myself to toss an assertion of a Moorean proposition into a casual conversation at my local climbing gym and observe how my audience reacted. Perhaps unsurprisingly, my climbing partners were exceptionally good at applying the principle of charity and updating their interpretation of what I'd said accordingly ("oh, she must mean that before she looked out the window, she believed that it wasn't raining when in fact it was"). Getting people to see the absurdity of what 
but the trouble is that it does not go far enough. For although Moore did not seem to notice that Moorean propositions also generate a similar paradox for beliefs, it is easy to imagine a scenario in which an individual consciously believes ' $p$, but I don't believe that $p$ ' but does not assert it because, for example, she has a nasty case of laryngitis that prevents her from speaking. She does not confuse her audience-indeed, she has no audience-but her belief is no less absurd simply because she does not express it out loud. But it is hard to see exactly why this is so, if Woods is right that Moorean propositions are absurd because of their effect on the audience. He elaborates,

... when I sincerely assert $p$, I commit myself to, though I do not assert, my belief that $p$. It is this feature that gives rise to the incoherence of my utterance of the form ' $p$, but I don't believe that $p$ '. The incoherence is a result of my incurring a commitment I explicitly deny I meet. (Woods 2014: 2)

This is as close as Woods comes to recognizing that what explains the absurdity in standard cases of Moore's paradox will bottom out at something psychological, such as "incurred commitments." Unfortunately, all that Woods says about what ultimately explains the absurdity in standard cases of Moore's paradox is that there is something incoherent about incurring a commitment I explicitly deny I meet. So, Woods's solution to Moore's paradox depends on, but leaves entirely unexplained, the idea that there is something incoherent about the commitments a speaker incurs by asserting a Moorean proposition. And worse still, Woods never explains what exactly a commitment is, what it is to incur one, and what (if anything) distinguishes incurred commitments from beliefs. So we cannot simply appeal to these concepts in order to put together, on Woods's behalf, an account of why it is incoherent to incur commitments that seem to contradict each other. I conclude that Woods's solution to Moore's paradox is at best incomplete.

\section{Belief and Moore's Paradox}

Call assertions of Moorean propositions Moorean assertions and conscious believings of them Moorean beliefs. ${ }^{17}$ In the previous section, we saw that Woods's solu-

I'd said actually took a bit of poking and prodding. No doubt, my sample size is very small, but I suspect that many audiences are like mine in this way.

17. The reference to conscious beliefs in Moorean propositions is necessary since it appears to be a consensus position in the literature that such beliefs are only absurd when they are consciously held (Rosenthal 1995a; 1995b; Kriegel 2004). This makes sense, given the following sort of 
tion to Moore's paradox fails to generalize from Moorean assertion to Moorean belief. Moorean beliefs are absurd whether or not they are given linguistic expression through the speech act of assertion. Since the absurdity generated by Moore's paradox is not purely a linguistic phenomenon, purely linguistic solutions to Moore's paradox will fail to generalize in a way that accounts for the absurdity of Moorean beliefs. And this is a problem. An adequate solution to Moore's paradox must explain the absurdity of both Moorean assertions and Moorean beliefs (Shoemaker 1995: 213).

In fact, an adequate solution to Moore's paradox will do more than generalize from assertion to belief; it will also explain the absurdity of Moorean assertions in terms of the absurdity of the Moorean beliefs that they express. There is, after all, nothing wrong with uttering Moorean propositions when they do not express Moorean beliefs. An honest flight attendant who does not believe the schedule he's required to report to the passengers stuck on a delayed flight might conclude his announcement of the schedule with the disclaimer, "Personally I don't believe it."18 What is important for my purposes is just that the absurdity of asserting Moorean propositions can be derived exclusively from the absurdity of believing them. In the remainder of the paper, I follow Sydney Shoemaker's suggestion that, "an explanation of why one cannot assert a Mooreparadoxical sentence will come along for free, via the principle that what one can believe constrains what one can assert" (1995: 213). With Shoemaker, I assume that an account of the absurdity of Moorean beliefs is explanatorily prior to an account of the absurdity of Moorean assertions. More specifically, I assume that an account of the absurdity of consciously held Moorean beliefs is explanatorily prior to an account of the absurdity Moorean assertions. Or, in any event, expressivists who adopt this strategy can handily avoid Woods's objection.

example (adapted from Williams 2015a; 2015b). A painful conversation with a psychologist helps Peter exhume a repressed belief that his father physically abused him that persists in the face of his conscious conviction that he did not. Before Peter's visit to his psychologist, Peter held the pair of beliefs 'my father physically abused me' and 'I don't believe that my father physically abused me.' But Peter was not conscious or aware of the former belief, and so it seems unduly harsh to judge that Peter was guilty of absurdity even before he walked into his psychologist's office. Indeed, it is controversial whether Peter could even have been attributed an unconscious belief in the Moorean proposition 'my father abused me but I don't believe it,' since such a conjunctive belief arguably requires someone to hold both conjuncts in their mind at once - that is, for the belief to be conscious. In any event, I will assume that only conscious Moorean beliefs are absurd, and that an explanation of Moore's paradox need not have anything to say about unconscious beliefs. But for a discussion of the possibility that people can have unconscious beliefs in Moorean propositions, and that there is something at least "mildly" problematic about such beliefs, see Williams (2010).

18. This sort of case comes from Wittgenstein, who discusses a railway official who does not believe the schedule he must report to the passengers. He announces, "Train No. . . . will arrive at ... o'clock. Personally I don't believe it" (Wittgenstein 1980: 93). 


\section{The Absurdity in the Standard Case of Moore's Paradox, (D)}

Most accounts of the absurdity of Moorean belief diagnose it in terms of a manifestation of a certain kind of irrationality. Someone who believes a Moorean proposition violates a rational requirement that governs the relation between the belief that $p$ and the belief that not- $p$. Namely:

[No Contradictions] One cannot rationally hold the conscious belief $(p$ \& not- $p$ ).

Accounts that adopt this strategy attempt to show that given certain principles governing conscious belief, someone who believes a Moorean proposition has a belief with self-contradictory content. According to a simple version of this view-inspired by Shoemaker (1995), Thomas Baldwin (1990), Uriah Kriegel (2004), David Rosenthal (1995a; 1995b), and Jonathan Williams (2015a; 2015b) believing a Moorean proposition violates No Contradictions because of the following two principles governing conscious belief:

[Conjunction] One consciously believes ${ }^{19}$ that $(p \& q)$ if and only if one both consciously believes that $p$ and one consciously believes that $q \cdot{ }^{20}$

[Transparency of Belief] If one consciously believes that $p$, then one consciously believes that one believes that $p .^{21}$

A word on Conjunction and Transparency of Belief is in order. According to Conjunction, conscious belief both distributes and collects over conjunction. Suppose I consciously believe that my shoes are green and that Phoenix is the capital of Arizona. If conscious belief distributes over conjunction, then it follows that I consciously believe that my shoes are green and I consciously believe that Phoenix is the capital of Arizona. If conscious belief collects over conjunction, then if I consciously believe that the Arcade Fire is from Montreal and I consciously

19. Providing an explanation of what it is for a belief to be conscious is part of, well, a notoriously Hard Problem, so I would prefer not to commit myself to a particular explanation of conscious belief, at least if I can help it. The claim that conscious belief collects over conjunction (in the sense that I explain just down the page) will seem more or less controversial depending on one's preferred explanation of what it is for a belief to be conscious.

20. It is implausible that belief is closed under entailment in general, but the idea that believing a conjunction implies believing the first conjunct is an especially plausible form of doxastic closure. Or, at any rate, philosophers working on Moore's paradox (and surrounding issues) seem to take for granted that suitably qualified (conscious, first-order, de se) beliefs are closed under entailment in this way. See Williams (2015a; 2015b) for more on this.

21. This comes from Rosenthal (1995b) but Baldwin anticipates it in his (1990). 
believe that San Francisco is in California, it follows that I consciously believe that the Arcade Fire is from Montreal and that San Francisco is in California. ${ }^{22}$ According to Transparency of Belief, on the other hand, if I consciously believe that Istanbul is in Turkey, then I consciously believe that I believe that Istanbul is in Turkey. ${ }^{23}$

With these two principles in hand, it is possible to show that someone who consciously believes a Moorean proposition violates No Contradictions. For example, suppose I consciously believe 'it's raining, but I don't believe that it's raining'. By Conjunction, I thereby have a conscious belief that it's raining and a conscious belief that I don't believe that it's raining. By Transparency of Belief, I therefore have the conscious belief that I believe that it's raining. By Conjunction, I thereby have a conscious belief with the self-contradictory content: 'I believe that it's raining and I don't believe that it's raining'. In other words, someone who consciously believes 'it's raining, but I don't believe that it's raining' must, by Conjunction and Transparency of Belief, consciously believe both that she believes that it's raining and that she doesn't believe that it's raining. But that's a contradiction! So in standard cases, Moorean beliefs are absurd because they are manifestations of irrationality: they violate No Contradictions. And because of the expression relation that holds between sincere assertions and beliefsbecause I express my belief that $p$ by sincerely asserting that $p$-if Moorean beliefs are absurd then Moorean assertions are as well. This is the absurdity that is characteristic of standard cases of Moore's paradox such as (D).

This basic structure lies behind many popular solutions to Moore's paradox, though, of course, not everyone accepts this argument exactly as it is written. Philosophers squabble over exactly how to formulate the principles governing conscious belief, and in particular, exactly how to qualify Transparency of Belief to make plausible the transition from believing that $p$ to believing that one

22. For example, one might worry that the Lottery Paradox causes trouble for the claim that conscious belief collects over Conjunction, but these sorts of cases are not relevant to the issue at hand.

23. It does not follow from any suitably qualified version of Transparency of Belief that if I consciously believe that I believe that Istanbul is in Turkey, then I consciously believe that I consciously believe that I believe that Istanbul is in Turkey. Thus, Transparency of Belief may be rendered narrow in that the antecedent may be restricted to first-order beliefs to ward off the threat of this infinite series of beliefs. I left out this plausible qualification (as well as another, according to which the content of the belief in the antecedent is necessarily de se) because exactly how best to formulate these qualifications is controversial, and because this does not matter much for my purposes. See Kriegel (2004) and Williams (2015b) for discussion. Also worth noting is that Transparency of Belief does not license us to replace the believed content in the antecedent of Transparency of Belief with a co-referential expression in the consequent. For example, while Transparency of Belief implies that if I consciously believe that superman can fly, then I consciously believe that I believe that superman can fly, it does not imply further that I consciously believe that I believe that Clark Kent can fly. Thanks to an anonymous referee for raising this possibility.

Ergo $\cdot$ vol. 5, no. $36 \cdot 2018$ 
believes that $p$. Shoemaker, for instance, restricts the beliefs governed by the principle to those that are "available" to the believer in a particular way. When beliefs are available in this way, the believer is disposed to do things such as say "I believe that $p$ " (Shoemaker 1995: 218, 225-226). According to Shoemaker, these sorts of dispositions themselves constitute believing that one believes that $p$, which is supposed to suffice to explain why the transition is a kosher one. ${ }^{24}$ Kriegel (2004), on the other hand, along with Baldwin (1990), Rosenthal (1995a; 1995b), and Williams (2006; 2010) all focus explicitly on conscious beliefs, and maintain that for the transition from believing that $p$ to believing that one believes that $p$ to fall under the scope of the principle, the belief in the antecedent of Transparency of Belief must be first-order, and the belief in the consequent of the Transparency of Belief must be de se.

One might wish to reject my response to Woods on the grounds that Conjunction and Transparency of Belief cannot be the real explanation of the absurdity of Moorean beliefs because they are implausibly strong and controversial without suitable qualifications of the sort just mentioned. For my purposes here, however, I do not need to assume that the principles hold in full generality, but only that they hold in the specific instances where Moorean propositions sound absurd, since this is the sort of linguistic data Woods's argument relies on. And perhaps they need not hold even in all such cases. If what we want to explain is why expressions of Moorean beliefs sound absurd, all we need to hold is that the audience to whom the absurdity is apparent believes that the speaker forms beliefs in accordance with Conjunction and Transparency of Belief in these cases. In other words, Transparency of Belief can explain why expressions of Moorean beliefs sound absurd if the principle is a claim about the beliefs a linguistically competent audience would attribute to the speaker on the basis of her utterance. In this case, though we are no longer explaining the absurdity of a Moorean assertion in terms of the absurdity of the belief it expresses, we are still explaining the apparent absurdity of a Moorean assertion in terms of the absurdity of the belief it apparently expresses, thus retaining the spirit of Shoemaker's suggestion that we explain the absurdity of a Moorean expression in terms of the absurdity of Moorean belief. ${ }^{25}$

24. It also explains why Shoemaker offers Transparency of Belief as a biconditional: necessarily, if one is rational, then one believes that $p$ if and only if one believes that one believes that $p$. Notice also that for Shoemaker, Transparency of Belief is not merely a descriptive claim about conscious belief, but a rational requirement. I return to the possibility of treating this principle as a rational requirement later.

25. Thanks to an anonymous reviewer for pressing me on this point. 


\section{The Absurdity in the Emotive Cases of Moore's Paradox, (A-B)}

One advantage of the explanation just given is that it can be straightforwardly generalized to provide a unified explanation of Woods's emotivist Moorean propositions, (A) and (B). Recall Woods's claim that it is possible to reproduce the same absurdity present in standard Moore-paradoxical constructions using utterances such as 'Go Red Sox!' rather than sentences in the indicative. For example, Woods thinks that a sincere utterance of 'Go Red Sox!' conjoined with 'I don't support the Red Sox' yields the absurdity we find when we conjoin a sincere utterance of ' $p$ ' with 'I don't believe that $p$ '.

My explanation of the absurdity in standard cases of Moore's paradox can extend to these cases if we replace Transparency of Belief with the more general principle:

[Transparency of Attitudes] If one consciously holds an attitude, then one consciously believes that one has that attitude.

Transparency of Attitudes entails Transparency of Belief, but applies to all consciously held attitudes, rather than only consciously held beliefs. So suppose I sincerely utter 'Fuck the Yankees! I don't have any negative attitudes toward the Yankees', thereby expressing two distinct attitudes: (i) my consciously held negative attitudes toward the Yankees and (ii) my conscious belief that I don't have any negative attitudes toward the Yankees. Applying Transparency of Attitudes to (i) yields a conscious belief that I have negative attitudes toward the Yankees. So, I consciously believe that I have negative attitudes toward the Yankees and I consciously believe that I don't have any negative attitudes toward the Yankees. By Conjunction, I thereby have a conscious belief with selfcontradictory content: I consciously believe 'I have negative attitudes toward the Yankees and I don't have any negative attitudes toward the Yankees,' and this violates No Contradictions. Thus, if Transparency of Attitudes holds, we have a straightforward explanation of why emotive Moorean propositions generate the same absurdity we find in standard cases of Moore's paradox: they violate No Contradictions and therefore are manifestations of irrationality.

Transparency of Attitudes is stronger than Transparency of Belief, so if it is implausible that Transparency of Belief holds in full generality, then this should be even more implausible in the case of Transparency of Attitudes. But, once again, it is enough to appeal to the fact that this principle holds only in the specific instances where emotive Moorean propositions are absurd, or at the very least that in cases where emotive Moorean assertions sound absurd, we may explain this apparent absurdity by pointing to the fact that audiences attribute 
attitudes in accordance with Transparency of Attitudes in these contexts. For example, it seems clear enough that when someone sincerely utters 'Go Red Sox!' or 'Fuck the Yankees!' we do indeed attribute to the speaker a conscious belief that they hold a positive or negative noncognitive attitude towards a baseball team, as Transparency of Attitudes predicts. It is an interesting question why Transparency of Attitudes holds for some sincere expressions of attitudes but not others, or why we attribute beliefs in this way, and I will briefly return to this question in the next section. But what matters for now is that in cases where we do form or attribute attitudes in accordance with Transparency of Attitudes we have an explanation of the absurdity or apparent absurdity characteristic of Moore's paradox. On the other hand, when Transparency of Attitudes fails, we should not expect the absurdity characteristic of Moore's paradox, and we have an explanation of why: when Transparency of Attitudes fails, there is no way to derive a belief with self-contradictory content.

\section{Expressivism and the Moral Case of Moore's Paradox}

We are now in a good position to see how and why the failure of the transparency of expressivism to ordinary speakers surfaces in an analysis of Moore's paradox. Suppose first we attempt to derive this absurdity by relying only on Transparency of Belief. Consider the expressivist Moorean proposition (E), 'murder is wrong, but I don't disapprove of murdering'. The problem is that expressivist Moorean propositions like (E) do not express beliefs with self-contradictory content. This is because the belief that one believes that murder is wrong is not the negation of the belief that one doesn't disapprove of murdering. Following the steps of our previous derivation, we are able to show that someone who consciously believes (E) believes 'I believe that murder is wrong and I don't disapprove of murdering'. But that's not a contradiction! So unlike a standard Moorean proposition, someone who believes an expressivist Moorean proposition does not necessarily violate No Contradictions, at least if we constrain ourselves to Transparency of Belief.

What about Transparency of Attitudes? Believing an expressivist Moorean proposition would violate No Contradictions if both expressivism and Transparency of Attitudes were true. For according to expressivism, what it is to consciously believe that something is wrong is to consciously disapprove of it. And according to Transparency of Attitudes, when one consciously disapproves of something, one consciously believes that one disapproves of it. So together, expressivism and Transparency of Attitudes imply:

[Transparency of Moral Judgment] If one consciously believes that $x$ is wrong, then one consciously believes that one disapproves of $x$. 
For example, whereas Transparency of Belief implies that if one consciously believes that murder is wrong, then one consciously believes that one believes that murder is wrong, Transparency of Moral Judgment implies further that one consciously believes that one disapproves of murder. And when combined with Conjunction, Transparency of Moral Judgment does yield a conscious belief with self-contradictory content: someone who consciously believes 'murder is wrong, but I don't disapprove of murdering' must, by Conjunction and Transparency of Moral Judgment, consciously believe 'I believe that I disapprove of murdering and that I don't disapprove of murdering'. But that's a contradiction, and believing it violates No Contradictions. Thus, if Transparency of Moral Judgment plausibly governs our attitudes, then Woods is right: we should expect expressivist Moorean propositions to generate the absurdity as standard Moorean propositions. And furthermore, as before, we should expect the appearance of absurdity even in cases where Transparency of Moral Judgment fails to hold as a matter of fact, so long as it at least describes the attitudes a linguistically competent audience would attribute to a speaker on the basis of her utterance. If, when someone sincerely utters an expressivist Moorean proposition, her audience attributes to her attitudes in accordance with Transparency of Moral Judgment and Conjunction, then this utterance will appear absurd, since the audience will attribute to the speaker a belief with self-contradictory content.

But as we have already seen, no self-respecting expressivist would accept Transparency of Moral Judgment, either interpreted as a descriptive claim about the attitudes people actually have or a principle governing the attributions of attitudes, and for good reason. Transparency of Moral Judgment licenses replacing the explicitly moral statement 'I believe that murder is wrong' with its expressivist analysis 'I disapprove of murder'. So, according to Transparency of Moral Judgment, whenever someone consciously believes that something is wrong, she thereby believes that she disapproves of it, or at least her audience attributes attitudes to her in this way. In other words, if Transparency of Moral Judgment were true, then it would be transparent to someone who believes that murdering is wrong, or transparent to her audience, that she disapproves of murdering. But expressivists explicitly deny this. They explicitly deny that the truth of expressivism is transparent, as it would be if we necessarily believed either that we disapprove of everything that we believe is wrong or that others necessarily disapprove of everything that they believe is wrong (see Blackburn 1992: 172-173; 1996). And furthermore, expressivists allow that even competent users of moral language fail to form attitudes in accordance with Transparency of Moral Judgment, and that we fail to attribute attitudes to competent users in his way. ${ }^{26}$ So Transparency of Moral Judgment is neither true as a matter of fact,

26. Woods seems to think that being linguistically competent with moral language requires satisfying Transparency of Moral Judgment. Responding briefly to the objection that ordinary 
nor is it true as a necessary condition for linguistic competence, nor is it true as a principle governing our attribution to (linguistically competent) speakers. And since Transparency of Moral Judgment is essential to explain why believing an expressivist Moorean proposition violates No Contradiction, we have a perfectly good explanation of why these propositions fail to generate the characteristic absurdity. This is where the assumption of transparency surfaces in an analysis of Moore's paradox. ${ }^{27}$

Still, one might wish to revive Woods's objection by insisting we think instead of Transparency of Moral Judgment as a rational requirement:

[Rational Transparency of Moral Judgment] If one is rational and if one consciously believes that $x$ is wrong, then one consciously believes that one disapproves of $x$.

Rational Transparency of Moral Judgment is a putative rational requirement linking conscious moral beliefs to conscious beliefs about one's own noncognitive attitudes. According to Rational Transparency of Moral Judgment, someone who consciously believes that murder is wrong will, if she is rational, consciously believe that she disapproves of murdering. While we cannot use Rational Transparency of Moral Judgment to show that someone who consciously believes an expressivist Moorean proposition has a conscious belief with self-contradictory content, we can use it to show that someone who consciously believes an expressivist Moorean proposition necessarily violates a requirement of rationality: either she fails to satisfy Rational Transparency of Moral Judgment or else she fails to satisfy No Contradictions. ${ }^{28}$ According to this view, then, Moorean assertions are absurd because they are manifestations of this irrationality. ${ }^{29}$ And thus, if Rational Transparency of Moral Judgment is true, we should expect expressivist Moorean propositions and standard Moorean propositions to generate the same absurdity.

speakers find expressivist Moorean assertions felicitous because they do not know that expressivism is the correct account of moral discourse, Woods suggests that competent speakers tacitly acknowledge that by making moral assertions we incur commitments to having certain noncognitive attitudes, and that, given the truth of expressivism, this is not implausible. Expressivists disagree. See Blackburn (1984; 1998) and Gibbard (1990).

27. Thanks to two anonymous referees as well as the editors of Ergo for encouraging me to clarify precisely where the failure of transparency arises in the analysis of Moore's Paradox.

28. Declan Smithies offers an alternative account of Moore's paradox which, rather than attempting to derive a conscious belief with self-contradictory content, attempts to show that belief in the first conjunct justifies belief in the negation of the second conjunct. This is an interesting strategy, but for my purposes, what matters is that Smithies argument also relies on a belief in the first conjunct of a Moorean proposition being a negation of the second conjunct. See Smithies (2012).

29. In fact, one might think of Transparency of Belief or Conjunction as rational requirements, too. This is Shoemakers's own view (1995). (For more on Shoemaker's view, see Footnote 27.) Nothing turns on this.

Ergo $\cdot$ vol. 5, no. $36 \cdot 2018$ 
Contemporary defenders of expressivism have not, to my knowledge, said anything about Rational Transparency of Moral Judgment, but there are good reasons for them to reject it (and the associated principle that we attribute people attitudes in accordance with it). Unlike Transparency of Moral Judgment, Rational Transparency of Moral Judgment does not rely on the assumption of transparency, but it does require that failures of transparency are irrational. And it does not take much to see why one might wish to reject this interpretation of the principle on the grounds that it undermines the rationality of our moral practices. Defenders of expressivism claim that Transparency of Moral Judgment is false: they claim that ordinary people who are competent users of moral language systematically fail to grasp fully the nature of the attitudes that their moral judgments (or the moral judgments of others) express. But to reject Transparency of Moral Judgment while accepting Rational Transparency of Moral Judgment is to label all of these people irrational. This is a bad thing because it certainly seems as though people are able to engage rationally in our moral practices, irrespective of their metaethical views. And it is likely to be especially unattractive to defenders of expressivism, who take pains to show that their view accommodates all the features of our moral practices. ${ }^{30}$ It would be a Pyrrhic victory for expressivism if it could accommodate these important features of our moral practices only by labeling nearly all of its participants irrational, or, on the attributional version of the principle, by holding that we go around labeling people irrational in this way. So expressivists have ample reason to reject Rational Transparency of Moral Judgment, independently of its implications for Moore's paradox.

To sum up, I have argued that there is a straightforward explanation of why expressivist Moorean propositions do not generate the absurdity characteristic of standard cases of Moore's paradox. One does not necessarily violate a requirement of rationality by believing an expressivist Moorean proposition because it need not be transparent to someone who believes that murdering is wrong that she disapproves of murdering, even if she is rational and a competent user of moral language; furthermore, audiences do not attribute attitudes in this way. So Transparency of Moral Judgment fails as a descriptive claim, as a requirement for linguistic competency or rationality, and as a principle by which we attribute attitudes to speakers. All of this is compatible with the plausibility of Transparency of Belief, which is all we need to generate the absurdity in the standard

30. One of these features is precisely that we express our disapproval of murder not by shouting 'Boo to murder!' but rather by asserting 'murder is wrong'. Defenders of expressivism claim that their view can accommodate our use of these moral assertions. Another of these features is the tight connection between sincere assertion and belief according to which sincerely asserting that $p$ implies that the speaker believes that $p$. Defenders of expressivism also claim that their view can accommodate that sincerely asserting a moral proposition such as 'murder is wrong' implies that the speaker believes that murder is wrong. The critical expressivist move here is to adopt a highly deflationary understanding of belief that falls out of endorsing semantic minimalism.

Ergo $\cdot$ vol. 5, no. $36 \cdot 2018$ 
case. Thus, we may explain why standard Moorean propositions are absurd and expressivist Moorean propositions are not without rejecting the parity thesis.

In our explanation of the absurdity of emotive Moorean propositions, however, we relied not just on Transparency of Belief, but Transparency of Attitudes. And, as we have seen, if expressivism were true, then Transparency of Moral Judgment would follow from Transparency of Attitudes. So we return to the earlier question of why Transparency of Attitudes holds for some conscious attitudes and not others, as expressivists must insist if they are to acknowledge the absurdity of emotive Moorean propositions without claiming that expressivist Moorean propositions are absurd as well. Why is it that some consciously held attitudes - for example, beliefs in typical cases, and negative and positive attitudes expressed by cheering on or cursing at sports teams-are transparent whereas others - most notably, the noncognitive attitudes that are expressed by moral utterances - are not? Is this just an ad hoc distinction, posited only to save the expressivist research program? Or are there more principled grounds for distinguishing between cases where Transparency of Attitudes does and does not hold?

Although I cannot provide a full explanation of this phenomenon here, I suspect that a plausible explanation will haves something to do with our social and linguistic practices, and the different competency and sincerity conditions that attach to these practices. When someone utters an interjection like, 'Fuck the Yankees!' and we take her to be sincere, we do attribute to her a strong negative attitude toward the Yankees, which, we assume is just as transparent to her as it is to us. Someone who says, "Fuck the Yankees!" without consciously believing that she has negative attitudes towards the Yankees, is, we think, either insincere or else incompetent when it comes to cheering for or against sports teams. But it is precisely this that expressivists deny in the case of moral language. Expressivists deny that, as a matter of social and linguistic practice, we necessarily attribute to sincere, competent moral speakers who utter 'Murder is wrong' an attitude of disapproval toward murdering that is necessarily transparent to her. Whereas someone cannot sincerely and competently engage in sports discourse without understanding that cheering for and against sports teams expresses positive or negative attitudes, expressivists allow that someone can sincerely and competently engage in moral discourse without believing that her expressions of moral attitude amount to expressions of disapproval rather than, say, ordinary beliefs. Otherwise, expressivists would have to insist that anyone who uses moral language without subscribing to expressivism is necessarily either incompetent or insincere. Perhaps some hold these views in private company, but it is not the official party line. 


\section{Conclusion}

Woods argues that Moore's paradox reveals that a central tenet of expressivism, the parity thesis, is false. The arguments in this paper have been primarily defensive. I have shown that defenders of expressivism who accept the parity thesis have at their disposal a good response to the argument Woods advances against their view. The response is to reject the first premise of the argument and deny that Moore's paradox is a good test of the parity thesis. In standard cases, Moorean beliefs are absurd because by believing ' $p$, but I don't believe that $p$ ', one has a conscious belief with self-contradictory content, which violates a rational requirement; and a similar analysis holds for emotive Moorean propositions. On the other hand, one does not necessarily violate a rational requirement by believing an expressivist Moorean proposition because Transparency of Moral Judgment fails as a descriptive claim, a condition for linguistic competence, and a rational requirement. It need not be transparent to someone who believes that murdering is wrong that she disapproves of murdering, even if she is rational and a competent user of moral language. So the parity thesis is out of the Woods: expressivists may continue to maintain that moral assertions express noncognitive attitudes in just the way that ordinary, descriptive assertions express beliefs.

Nevertheless, Woods's argument invites-indeed requires-both friends and foes of expressivism to think carefully about the transparency of our moral attitudes. What explains why some sincere expressions of attitudes (such as interjections, and perhaps pejoratives) are transparent whereas others are not? ${ }^{31}$ What explains why some failures of transparency seem to evince linguistic incompetence or irrationality whereas others do not? These are interesting and important questions for expressivists, to be sure, but they are no less pressing for those of us who find ourselves unsure of what view to accept. I have suggested the beginnings of an answer rooted in our social and linguistic practices, but more carefully developed answers are needed to help clarify the features of moral discourse that any plausible metaethical view must accommodate.

\section{Acknowledgements}

I am especially grateful to Jacob Barrett and Juan Comesaña for providing encouragement and inspiration as well as feedback on countless earlier drafts. Thanks also to Stew Cohen, Jamie Dreier, Alex Grossman, Nathan Robert Howard, Connie Rosati, Mark Timmons, Teemu Toppinen, Jason Turner, Jack Woods, the editors of Ergo, and two anonymous referees for useful comments and feedback.

31. See Joyce (2006: 51-58) for an interesting discussion of transparency and pejoratives.

Ergo • vol. 5, no. 36 • 2018 


\section{Works Cited}

Baldwin, Thomas (1990). G. E. Moore. Routledge.

Blackburn, Simon (1984). Spreading the Word: Groundings in the Philosophy of Language. Clarendon Press.

Blackburn, Simon (1992). Essays in Quasi-Realism. Oxford University Press.

Blackburn, Simon (1996). Blackburn Reviews Dworkin. Brown Electronic Article Review Service. Retrieved from http://www.brown.edu/Departments/Philosophy/ bears/961iblac.html

Blackburn, Simon (1998). Ruling Passions: A Theory of Practical Reasoning. Clarendon Press.

Cuneo, Terence (2006). Saying What We Mean: An Argument against Expressivism. In Russ Shafer-Landau (Ed.), Oxford Studies in Metaethics (Vol. 1, 35-71). Oxford University Press.

Dreier, James (2004). Lockean and Logical Truth Conditions. Analysis, 64(1), 84-91. https://doi.org/10.1093/analys/64.1.84

Finlay, Stephen (2014). Confusion of Tongues: A Theory of Normative Language. Oxford University Press. https://doi.org/10.1093/acprof:0so/9780199347490.001.0001

Gibbard, Allan (1990). Wise Choices, Apt Feelings: A Theory of Normative Judgment. Harvard University Press.

Gibbard, Allan (2003). Thinking How to Live. Harvard University Press.

Green, Mitchell S. and John Williams (2007). Moore's Paradox: New Essays on Belief, Rationality, and the First Person. Clarendon Press.

Heal, Jane (1994). Moore's Paradox: A Wittgensteinian Approach. Mind, 103(409), 5-24. https://doi.org/10.1093/mind/103.409.5

Hintikka, Jaakko (1962). Knowledge and Belief: An Introduction to the Logic of the Two Notions. Cornell University Press.

Jackson, Frank and Phillip Pettit (1998). A Problem for Expressivism. Analysis, 58(4), 239251. https://doi.org/10.1093/analys/58.4.239

Joyce, Richard (2006). The Evolution of Morality. MIT Press.

Kriegel, Uriah (2004). Moore's Paradox and the Structure of Conscious Belief. Erkenntnis, 61(1), 99-121. https://doi.org/10.1023/B:ERKE.0000037548.06150.b6

Moore, G. E. (1946). Russell's Theory of Descriptions. In Paul Arthur Schilpp (Ed.), The Philosophy of Bertrand Russell (175-225). Open Court.

Moore, G. E. (2013). G.E. Moore: Selected Writings (Thomas Baldwin, Ed.). Taylor and Francis.

Olson, Jonas (2010). The Freshman Objection to Expressivism and What to Make of It. Ratio, 23(1), 87-101. https://doi.org/10.1111/j.1467-9329.2009.00452.x

Rosenthal, David M. (1995a). Moore's Paradox and Consciousness. Philosophical Perspectives, 9, 313-333. https://doi.org/10.2307/2214224

Rosenthal, David M. (1995b). Self-Knowledge and Moore's Paradox. Philosophical Studies, 77(2/3), 195-209. https://doi.org/10.1007/BFoo989569

Schroeder, Mark (2008a). Expression for Expressivists. Philosophy and Phenomenological Research, 76(1), 86-116. https://doi.org/10.1111/j.1933-1592.2007.00116.x

Schroeder, Mark (2008b). Being For: Evaluating the Semantic Program of Expressivism. Clarendon Press. https://doi.org/10.1093/acprof:0so/9780199534654.001.0001

Schroeder, Mark (2014). Does Expressivism Have Subjectivist Consequences? Philosophical Perspectives, 28(1), 278-290. https://doi.org/10.1111/phpe.12048 
Shoemaker, Sydney (1995). Moore's Paradox and Self-Knowledge. Philosophical Studies, 77(2/3), 211-228. https://doi.org/10.1007/BFoo989570

Shoemaker, Sydney (1988). On Knowing One's Own Mind. Philosophical Perspectives, 2, 183-209. https://doi.org/10.2307/2214074

Smithies, Declan (2012). Moore's Paradox and the Accessibility of Justification. Philosophy and Phenomenological Research, 85(2), 273-300. https://doi.org/10.1111/j.1933-1592.2011.00506.x

Suikkanen, Jussi (2009). The Subjectivist Consequences of Expressivism. Pacific Philosophical Quarterly, 90(3), 364-387. https://doi.org/10.1111/j.1468-0114.2009.01345.X

Toppinen, Teemu (2014). Expressivism and Moore's Paradox: A Reply to Woods. Journal of Ethics and Social Philosophy, 8(1). https://doi.org/10.26556/jesp.v8i1.16o

Toppinen, Teemu (2015). Relational Expressivism and Moore's Paradox. Journal of Ethics and Social Philosophy, 9(2). https://doi.org/10.26556/jesp.v9i2.173

Williams, John N. (2006). Moore's Paradoxes and Conscious Belief. Philosophical Studies, 127(3), 383-414. https://doi.org/10.1007/s11098-004-7826-x

Williams, John N. (2010). Moore's Paradox, Defective Interpretation, Justified Belief and Conscious Belief. Theoria, 76(3), 221-248. https://doi.org/10.1111/j.1755-2567.2010.01073.x

Williams, John N. (2013). Moore's Paradox and the Priority of Belief Thesis. Philosophical Studies, 165(3), 1117-1138. https://doi.org/10.1007/s11098-012-9997-1

Williams, John N. (2015a). Moore's Paradox in Speech: A Critical Survey. Philosophy Compass, 10(1), 10-23. https://doi.org/10.1111/phc3.12187

Williams, John N. (2015b). Moore's Paradox in Thought: A Critical Survey. Philosophy Compass, 10(1), 24-37. https://doi.org/10.1111/phc3.12188

Williamson, Timothy (2000). Knowledge and its Limits. Oxford University Press.

Wittgenstein, Ludwig (1980). Remarks on the Philosophy of Psychology. University of Chicago Press.

Woods, Jack (2014). Expressivism and Moore's Paradox. Philosophers Imprint, 14(5), 1-12.

Woods, Jack (2015). Expressivism Worth the Name: A Reply to Teemu Toppinen. Journal of Ethics and Social Philosophy, 9(1). https://doi.org/10.26556/jesp.v9i1.168 